WellBeing International

WBI Studies Repository

$11-2004$

\title{
Predators in Natural Fragments: Foraging Ecology of Wolves in British Columbia's Central and North Coast Archipelago
}

C. T. Darimont

University of Victoria

M. H. H. Price

University of Victoria

N. N. Winchester

University of Victoria

J. Gordon-Walker

Raincoast Conservation Society

P. C. Paquet

University of Calgary

Follow this and additional works at: https://www.wellbeingintlstudiesrepository.org/bioeopp

Part of the Animal Studies Commons, Population Biology Commons, and the Terrestrial and Aquatic Ecology Commons

\section{Recommended Citation}

Darimont, C. T., Price, M. H. H., Winchester, N. N., Gordon-Walker, J., \& Paquet, P. C. (2004). Predators in natural fragments: foraging ecology of wolves in British Columbia's central and north coast archipelago. Journal of Biogeography, 31(11), 1867-1877.

This material is brought to you for free and open access by WellBeing International. It has been accepted for inclusion by an authorized administrator of the WBI Studies Repository. For more information, please contact wbisr-info@wellbeingintl.org.

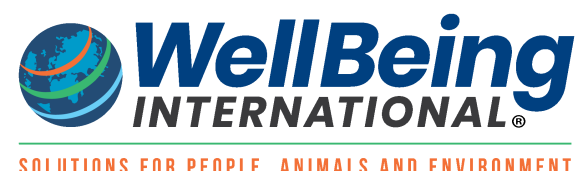




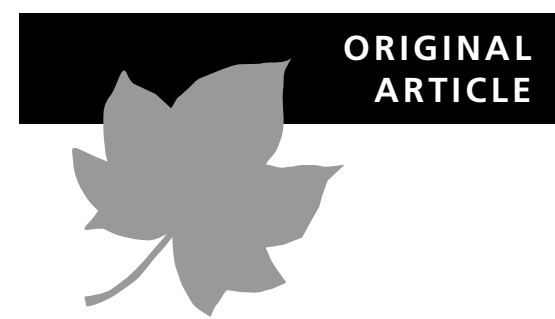

${ }^{1}$ Department of Biology, University of Victoria, Victoria, ${ }^{2}$ Raincoast Conservation Society, Bella Bella, B.C. and ${ }^{3}$ Faculty of Environmental Design, University of Calgary, Calgary, Alberta, Canada

${ }^{\star}$ Correspondence: C. T. Darimont, Department of Biology, University of Victoria, PO Box 3020, Victoria, B.C. Canada, V8W 3N5.

E-mail: cdarimon@uvic.ca

\section{Predators in natural fragments: foraging ecology of wolves in British Columbia's central and north coast archipelago}

\author{
C. T. Darimont ${ }^{1,2 \star}$, M. H. H. Price ${ }^{1}$, N. N. Winchester ${ }^{1}$, J. Gordon-Walker ${ }^{2}$ \\ and P. C. Paquet ${ }^{2,3}$
}

\begin{abstract}
Aim Predator-prey dynamics in fragmented areas may be influenced by spatial features of the landscape. Although little is known about these processes, an increasingly fragmented planet underscores the urgency to predict its consequences. Accordingly, our aim was to examine foraging behaviour of an apex mammalian predator, the wolf (Canis lupus), in an archipelago environment.
\end{abstract}

Location Mainland and adjacent archipelago of British Columbia, Canada; a largely pristine and naturally fragmented landscape with islands of variable size and isolation.

Methods We sampled 30 mainland watersheds and 29 islands for wolf faeces in summers 2000 and 2001 and identified prey remains. We examined broad geographical patterns and detailed biogeographical variables (area and isolation metrics) as they relate to prey consumed. For island data, we used Akaike Information Criteria to guide generalized linear regression model selection to predict probability of black-tailed deer (main prey; Odocoileus hemionus) in faeces.

Results Black-tailed deer was the most common item in occurrence per faeces (63\%) and occurrence per item (53\%) indices, representing about $63 \%$ of mammalian biomass. Wolves consumed more deer on islands near the mainland (65\% occurrence per item) than on the mainland (39\%) and outer islands (45\%), where other ungulates (mainland only) and small mammals replaced deer. On islands, the probability of detecting deer was influenced primarily by island distance to mainland (not by area or inter-landmass distance), suggesting limited recolonization by deer from source populations as a causal mechanism.

Main conclusions Although sampling was limited in time, consistent patterns among islands suggest that population dynamics in isolated fragments are less stable and can result in depletion of prey. This may have important implications in understanding predator-prey communities in isolation, debate regarding wolfdeer systems and logging in temperate rain forests, and reserve design.

\section{Keywords}

Archipelago, British Columbia, black-tailed deer, Canis lupus, conservation, foraging, fragmentation, islands, Odocoileus hemionus, wolf.

\section{INTRODUCTION}

Islands have been considered natural laboratories to study evolutionary and ecological process (Gorman, 1979; Williamson, 1981). Investigations of oceanic archipelagos have revealed how island communities are related to area, isolation and other island characteristics (e.g. MacArthur \& Wilson, 1967; Abbott, 1974; Kadmon \& Pulliam, 1993; Conroy et al., 1999). Biogeographical features, however, may also exert influence at the population level, including the mediation of predator-prey 
dynamics on islands or in other fragmented systems (Kareiva, 1990; Kareiva \& Wennergren, 1995; Dolman \& Sutherland, 1997). A predator's niche breadth can be predicted by the diversity and abundance of potential prey species (MacArthur \& Pianka, 1966), which may differ among islands. The limitations imposed by island geography, for example, may restrict prey species available to predators. For some consumers, however, foraging constraints on small or isolated oceanic islands may be mitigated by nutrient subsidies from the ocean, as recent investigations have revealed the coupled nature of marine-terrestrial ecosystems (Polis \& Hurd, 1995; Rose \& Polis, 1998; Reimchen, 2000).

The amplitude of predator and prey fluctuations reflect ecological conditions (Ricklefs, 1990), which may be unique in archipelagos or in other systems fragmented naturally or by humans. Predator-prey dynamics in isolation may be volatile, resulting in large amplitudes of predator and prey, or the extirpation of predator, prey, or both (Taylor, 1984). For example, the wolf-moose (Canis lupus - Alces alces) system on $540 \mathrm{~km}^{2}$ Isle Royale, Michigan, is separated by $36 \mathrm{~km}$ to the mainland. There, wolves and moose have experienced extreme fluctuations in abundance that is at least partially associated with their interaction (Peterson et al., 1984; Peterson \& Page, 1988; Vucetich \& Peterson, in press). Similar process has also been examined with smaller taxa in experimental designs. Populations of an herbivorous spider mite (Tetranychus urticae) and a predatory mite (Phytoseiulus persimilis) are highly unstable on isolated bean plants (Phaseolus lunatus) and can ultimately result in extinction of both (McCauley et al., 2000).

Knowledge about predator-prey dynamics in patchy landscapes is valuable because the planet is becoming increasingly fragmented by human activities (Saunders et al., 1991; Fahrig, 1997, 2003). Moreover, predators are more likely to decline or become extinct in fragments (Woodroffe \& Ginsberg, 1998), possibly resulting in mesopredator release and other ecosystem-wide consequences (Crooks \& Soulé, 1999; Terborgh et al., 2001). Conversely, even the effects of native predators on endangered prey can be severe in fragmented environments (Schneider, 2001). Consequently, archipelagos may provide model systems in which to predict the effects of size and isolation on predator-prey dynamics.

The temperate rain forest archipelago of British Columbia (BC) is an ideal system in which to address the influence of area and isolation of fragments on predator-prey systems. This remote and nearly pristine region is naturally fragmented, comprised of dozens of islands $<0.1$ to $>13 \mathrm{~km}$ apart (Fig. 1). Here, the wolf-black-tailed deer (Odocoileus hemionus) association forms the dominant mammalian predator-prey system, in which both animals can occupy all islands, at least ephemerally (Darimont \& Paquet, 2000, 2002). Herein, we examine spatial variability of resource use during spring and summer by examining wolf faeces from BC's central and north coast mainland and 29 islands of the adjacent archipelago. Theory of predator-prey systems in fragments suggests that area and isolation effects can strongly influence population dynamics, including processes associated with the depletion of prey (Kareiva, 1990; Kareiva \& Wennergren, 1995; Dolman \& Sutherland, 1997; McCauley et al., 2000). Moreover, the marine-terrestrial interface and the heterogeneous landscape of our study area offer a broad potential niche to wolves. Accordingly, on smaller and/or more isolated islands, we predicted a departure from a diet dominated by their main prey (deer) to one that includes considerable use of alternative resources. Our objectives herein are to identify prey species consumed by wolves of British Columbia's archipelago during spring and summer and to examine variability in wolf foraging behaviour as it relates to area and isolation of islands.

\section{METHODS}

\section{Study area}

We collected wolf faeces on BC's coast between the Kshwan Valley $\left(55^{\circ} 37^{\prime} \mathrm{N}, 129^{\circ} 48^{\prime} \mathrm{W}\right)$ in the north and the Koeye River $\left(51^{\circ} 46^{\prime} \mathrm{N}, 127^{\circ} 53^{\prime} \mathrm{W}\right)$ in the south (Fig. 1). This large, nearly roadless, and mostly unsettled region is bounded by the Coast Mountain range and Pacific Ocean to the east and west, respectively. Most of the low elevation forest is within the Coastal Western Hemlock biogeoclimatic zone (Pojar \& Mackinnon, 1994). Habitat heterogeneity in these temperate rain forests corresponds to landscape variability, which includes the following general regions: mountainous mainland, topographically complex inner islands, and flatter outer islands. Island sizes range from $5.0 \mathrm{~km}^{2}$ (Moore) to $2295 \mathrm{~km}^{2}$ (Princess Royal), distances to mainland $250 \mathrm{~m}$ to $13.05 \mathrm{~km}$, and distances among landmasses 0.05-7.25 km (Fig. 1).

Potential prey base is diverse, including black-tailed deer, moose, mountain goat (Oreamnos americanus), beaver (Castor canadensis), black bear (Ursus americanus), river otter (Lontra canadensis), plus smaller mustelids, rodents and birds. Five species of spawning salmonids (Onchorynchus spp.), crustaceans, molluscs and marine mammals are also available to wolves (Darimont \& Paquet, 2000, 2002), although salmon were not yet spawning widely when sampling occurred.

\section{Faecal collection}

During June and July 2000, and June and August 2001, we collected faeces in 30 mainland watersheds and on 29 islands (typically one to two sites per island). Sampling sites were selected non-randomly but were well distributed throughout the study area (Fig. 1). At each location, we surveyed beaches, estuaries and forests of the beach fringe, often on wildlife trails. We also surveyed logging roads when encountered, circumnavigated beaver ponds, and walked forest ridgelines. Surveys rarely extended $>5 \mathrm{~km}$ inland.

We stored faeces in plastic bags and froze them until analysis at the University of Victoria. Faeces can decompose rapidly in this wet environment (Wallmo et al., 1962; C.T. Darimont unpublished data). Therefore, we assumed the samples represented late spring and summer diets of wolves. 


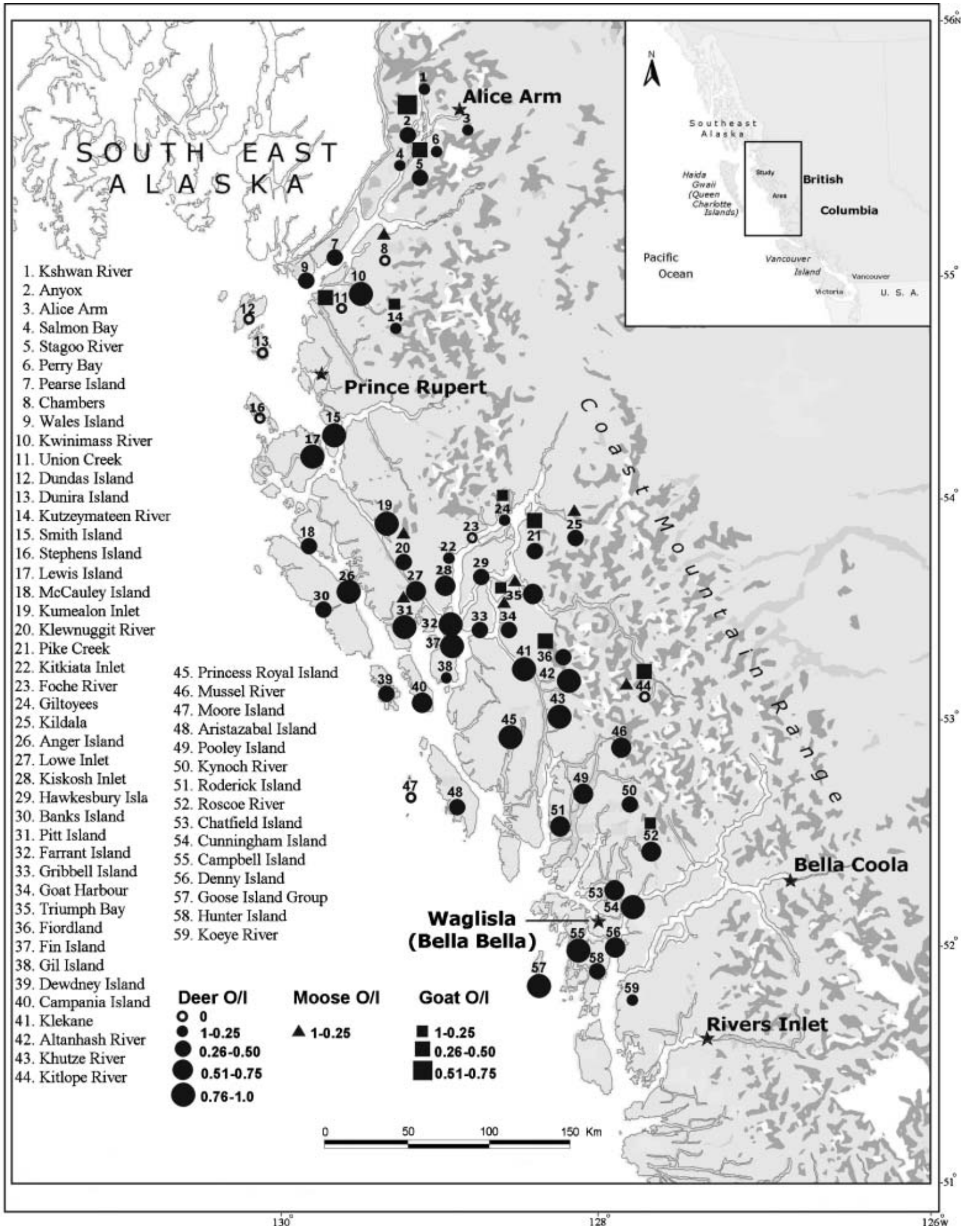

Figure 1 Study area where wolf (Canis lupus) faeces were collected in coastal British Columbia, Canada, during summers 2000 and 2001. Fifty-nine sampled islands and mainland watersheds numbered. Sampling extended from the Kshwan River (1) in the north to the Koeye River (59) in the south. Also shown are symbols denoting occurrence per item data for ungulates consumed (deer, Odocoileus hemionus; moose, Alces alces and goat, Oreamnos americanus). 


\section{Prey item identification and reporting}

Identification of prey followed Ciucci et al. (1996) and Kohira \& Rexstad (1997). Samples were autoclaved, then soaked and rinsed in a $1 \mathrm{~mm}$ mesh sieve until only hair, bone fragments and other macroscopic components remained. Mammalian prey was identified by comparing hair in faeces with voucher samples and use of dichotomous keys and dissecting microscope (magnification 20-40×; Mathiak, 1938; Mayer, 1952; Stains, 1958). When identification was uncertain $(n=60$ scats), scale imprints from a few guard hairs melted in acetate were examined using a compound microscope (magnification 40-400×). Non-mammal prey, such as fish, bird, and marine invertebrates, were identified by bones, teeth, feathers and shell fragments. Birds and small rodents (i.e. rodents smaller than beaver) were not identified further than class and order respectively. To eliminate inter-observer bias, only one person identified prey remains (MP) and only after a lengthy training period (c. $40 \mathrm{~h})$. We estimated precision by re-sampling approximately $10 \%$ of samples $(n=59)$, in which prey remains were consistently identified in 58 cases $(98 \%)$.

We report occurrence per faeces $(\mathrm{O} / \mathrm{F})$ index for comparison with published literature but use the occurrence per item $(\mathrm{O} / \mathrm{I})$ index in statistical tests as the former can be problematic because it exceeds unity when summed (Kohira \& Rexstad, 1997). These two metrics are important when faeces often contain more than one item (see Results). $\mathrm{O} / \mathrm{F}$ is the frequency by which an item occurs in faecal samples, whereas $\mathrm{O} / \mathrm{I}$ is the item's frequency among all items identified in all faeces combined. We also estimated mammalian biomass consumed using a regression equation estimated by Weaver (1993): $Y=0.439+0.008 X$, where $Y$ is the estimated biomass of prey consumed per faecal sample and $X$ is the mass of prey. Although masses may differ among age and sex classes, and wolves may kill unequal ratios of these classes, we used mean masses of adults reported in Cowen \& Guiguet (1975) and assumed a 1: 1 sex ratio. For deer, however, we distinguished between adults and fawns for biomass calculations using diagnostic hair diameter and colour characters, which are useful until the autumn (Scott, 1979). By necessity, biomass estimates excluded non-mammalian prey $(n=124$ of 705 items identified).

\section{Statistical analyses}

\section{General geographical patterns in foraging ecology}

We tested for general geographical patterns in foraging ecology among three areas that are associated with general habitat differences: mainland, inner islands, and outer islands. We defined inner islands as those directly adjacent to the mainland and outer islands as those that are not, irrespective of distance to mainland. This classification is consistent with mainland, southern inner island, and southern outer island biogeographical sub-regions defined in southeast Alaska, which are based on presence of endemic species and unique combinations of native taxa (MacDonald \& Cook, 1996). We compared O/I indices for deer, other ungulates (moose, goat), and small mammals among these areas using ANova or Kruskal-Wallis tests. We repeated these tests with indices relating to the proportion of total biomass represented by these taxa.

\section{Examining area and isolation effects on islands}

General geographical patterns, although informative, cannot adequately address the influence of area and isolation on predator-prey dynamics. For example, an inner island, next to the mainland, may be more isolated from other landmasses by water barriers compared with a collection of nearby outer islands. Thus we examined how biogeographical parameters, area (AREA), distance to mainland (MDIST), and interlandmass distance (LDIST) affected the probability of deer occurring in faecal remains on islands. We used these two isolation metrics to disentangle the possible influences of distance from the mainland, which may be the ultimate source for prey colonization, and distance to other landmasses, which likely provide the most available sources for prey colonization.

We measured MDIST as the shortest island-to-mainland distance or sum of island-to-island distances to mainland excluding distances across islands, whichever was shorter (Conroy et al., 1999). LDIST was the minimum distance to landmasses $>75 \mathrm{~km}^{2}$ (either mainland or island), roughly the size of Coronation Island, in nearby southeast Alaska, on which a small population of wolves existed for 8 years (Klein, 1996). All geographical parameters were estimated using marine charts (Canadian Hydrographic Service, Ottawa, Ontario) and Geographic Information Systems (Darimont \& Paquet, 2002).

We formed exploratory a priori hypotheses to explain how these biogeographical features would affect the probability of deer occurring in wolf faeces on islands, which were based on our knowledge of the area and ecological theory described above. From these hypotheses, we developed a set of candidate generalized linear regression models (binary logistic form). These were restricted to combinations of one to three of the identified (and untransformed) parameters and two-way interaction terms. We considered islands as the experimental unit, with the number of faeces containing deer as events and the total number of faeces as trials. A Hosmer-Lemeshow goodness-of-fit statistic based on the global model showed the data did not depart from a logistic-regression model $(P=0.475)$. Multicollinearity diagnostics suggested only weak interdependencies among predictor variables (Variance Inflation Factors range: 1.076-1.709). For each model, we calculated Akaike Information Criteria, adjusted for small sample sizes $\left(\mathrm{AIC}_{\mathrm{c}}\right)$, following the formula: $\mathrm{AIC}_{\mathrm{c}}=-2(\log$ likelihood $)+2 K+2 K(K+1) /(n-K-1)$, where $K$ is the number of parameters and $n$ the number of sampled islands. We then evaluated $\Delta \mathrm{AIC}_{\mathrm{c}}$ to select best approximating model(s) and make appropriate inference, using $\Delta \mathrm{AIC}_{\mathrm{c}}<2$ to describe the top model set (offering substantial level of empirical support). Finally, we summed Akaike weights $\left(\omega_{\mathrm{i}}\right)$ across the top model 
set for each variable to rank them by importance (Burnham \& Anderson, 1998; Anderson et al., 2001). Tests were performed using SPSS 11.0 (SPSS Inc., Chicago, IL, USA) and SAS 8 (SAS Inc., Cary, NC, USA).

\section{RESULTS}

Coastal wolves showed a wide dietary niche across the heterogeneous landscape (Table 1). We collected a mean of 8.77 samples at mainland sites (range $1-36 ; \mathrm{SD}=1.65$; $n=263$ ) and 11.45 at island sites (range $1-64 ; \mathrm{SD}=3.24$; $n=332$ ). Of 705 food items identified, black-tailed deer was the most common item in both occurrence/faeces and occurrence/item indices, followed by salmon, mountain goat, bird, mustelids, intertidal organisms, black bear, beaver, mink, moose and small mammals (Table 1). Biomass estimates demonstrated a different order of occurrence, with ungulates (deer, goat, moose) representing a combined $82.3 \%$ of mammal biomass consumed (Table 1). Grizzly bear (Ursus arctos), fisher (Martes pennanti), harbour seal (Phoca vitulina) and wolf each occurred once. We could not identify six items.

Foraging patterns of wolves differed among areas. Fifteen species occurred in mainland samples and 13 in island samples. Mountain goat, grizzly bear and fisher were found exclusively at mainland locations, whereas the sample containing seal was collected on an island. Goat remains were restricted to areas in or near rocky inlets, whereas moose remains, although near inlets, had a greater distribution, including on one island (Fig. 1).
Differences we observed in detection of deer and non-deer prey provide evidence of major changes in predation regime among geographical areas. Generally, deer dominated the diet on inner islands whereas other ungulates (goat, moose) and small mammals collectively occurred approximately as often as deer at mainland and outer island sites. Differences in occurrence/item among mainland, island, and outer island sites for deer approached significance (ANOVA; $F_{2,56}=2.967$, $P=0.060)$ and was highest on inner islands, but differed little between mainland and outer islands (Fig. 2a). Similarly, proportion of total mammalian biomass represented by deer also was highest on inner islands and varied little between mainland and outer islands sites (ANOVA; $F_{2,56}=6.972$, $P=0.002$; Fig. 2b). Other ungulates (moose, goat) represented significantly higher occurrence/item (Kruskal-Wallis $H$-test; $\chi^{2}=14.961 ; P=0.001$; Fig. 2a) and proportion of mammalian biomass (Kruskal-Wallis $H$-test; $\chi^{2}=14.885$; $P=0.001$; Fig. 2b) on mainland sites compared with extremely low or nil values on inner and outer islands respectively. In place of deer, wolves also foraged on small mammals, which generally occured more frequently at mainland and outer island sites compared with inner islands (Fig. 2a,b), but this difference was not significant in occurrence/item (Kruskal-Wallis $H$-test; $\chi^{2}=1.775 ; P=0.412$ ) or proportion of total mammalian biomass (Kruskal-Wallis $H$-test; $\left.\chi^{2}=1.120 ; P=0.571\right)$.

Model selection and multimodel inference suggest that among island sites, isolation was more important than area in predicting departure from a diet dominated by deer.

Table 1 Prey items identified in 595 wolf (Canis lupus) faeces collected summers 2000 and 2001 on the mainland and archipelago of coastal British Columbia

\begin{tabular}{|c|c|c|c|c|c|c|c|c|c|c|}
\hline \multirow[b]{2}{*}{ Prey taxa } & \multicolumn{3}{|c|}{ Mainland sites } & \multicolumn{3}{|c|}{ Island sites } & \multicolumn{3}{|c|}{ All sites combined } & \multirow[b]{2}{*}{ Biomass (\%) } \\
\hline & $n$ & $\mathrm{O} / \mathrm{F}(\%)$ & $\mathrm{O} / \mathrm{I}(\%)$ & $n$ & $\mathrm{O} / \mathrm{F}(\%)$ & $\mathrm{O} / \mathrm{I}(\%)$ & $n$ & $\mathrm{O} / \mathrm{F}(\%)$ & $\mathrm{O} / \mathrm{I}(\%)$ & \\
\hline Odocoileus hemionus (deer) & 124 & 47.1 & 39.5 & 250 & 75.3 & 63.9 & 374 & 62.7 & 53.0 & 64.6 \\
\hline Onchorynchus spp. (salmon) & 21 & 8.0 & 6.7 & 25 & 7.5 & 6.4 & 46 & 7.7 & 6.5 & N/A \\
\hline Oreamnos americanus (goat) & 37 & 14.1 & 11.8 & 0 & 0.0 & 0.0 & 37 & 6.2 & 5.3 & 9.1 \\
\hline Aves (birds) & 15 & 5.7 & 4.8 & 22 & 6.6 & 5.6 & 37 & 6.2 & 5.3 & N/A \\
\hline Martes americana (marten) & 20 & 7.6 & 6.4 & 14 & 4.2 & 3.6 & 34 & 5.7 & 4.8 & 2.9 \\
\hline Mustela erminea (ermine) & 25 & 9.5 & 8.0 & 8 & 2.4 & 2.1 & 33 & 5.5 & 4.7 & 2.7 \\
\hline Lontra canadensis (otter) & 10 & 3.8 & 3.2 & 15 & 4.5 & 3.8 & 25 & 4.2 & 3.6 & 2.1 \\
\hline Intertidal organisms & 13 & 4.9 & 4.1 & 12 & 3.6 & 3.1 & 25 & 4.2 & 3.6 & N/A \\
\hline Ursus americanus (bear) & 9 & 3.4 & 2.9 & 9 & 2.7 & 2.3 & 18 & 3.0 & 2.6 & 5.8 \\
\hline Castor canadensis (beaver) & 6 & 2.3 & 1.9 & 10 & 3.0 & 3.0 & 16 & 2.7 & 2.3 & 2.1 \\
\hline Mustela vison (mink) & 4 & 1.5 & 1.3 & 12 & 3.6 & 3.1 & 16 & 2.7 & 2.3 & 1.3 \\
\hline Alces alces (moose) & 11 & 4.2 & 3.5 & 1 & 0.0 & 0.0 & 12 & 2.0 & 1.7 & 8.6 \\
\hline Small rodents & 5 & 1.9 & 1.6 & 3 & 0.9 & 0.8 & 8 & 1.3 & 1.1 & 0.7 \\
\hline Vegetation & 9 & 3.4 & 2.9 & 5 & 1.5 & 1.3 & 14 & 2.4 & 2.2 & N/A \\
\hline Other ${ }^{*}$ & 5 & 1.9 & 1.6 & 5 & 1.5 & 1.3 & 10 & 1.7 & 1.4 & N/A \\
\hline Total & 314 & 119 & 100 & 391 & 117 & 100 & 705 & 118 & 100 & 100 \\
\hline
\end{tabular}

${ }^{*}$ Other represents single occurrence of brown bear (Ursus arctos), wolf, seal (Phoca vitulina) and fisher (Martes pennanti), plus six unidentified remains.

$n$, Number of items; O/F, occurrence/faeces; O/I, occurrence/item.

Biomass estimates are proportion of total mammalian biomass. Taxa organised by decreasing O/F and O/I for all sites combined. 

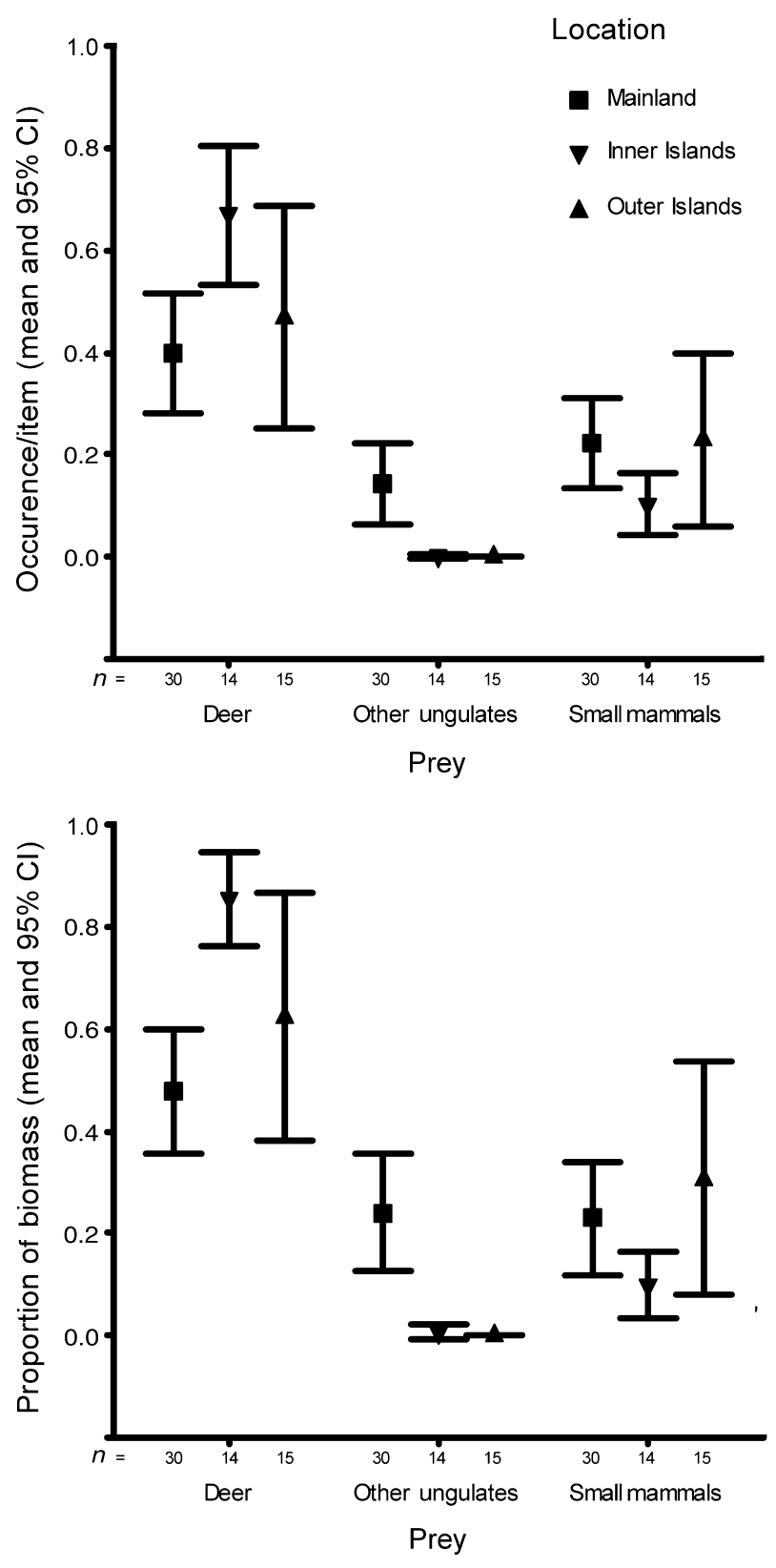

Figure 2 (a) Mean occurrence per item and (b) mean proportion of total mammalian biomass of prey detected in 595 wolf (Canis lupus) faeces from 59 sampling locations on the islands and mainland coast of British Columbia, Canada, summers 2000 and 2001. 'Small mammals' included river otter (Lontra canadensis), marten (Martes americanus), (ermine Mustela ermina), mink (Mustela vison), and rodent (Rodentia spp.). 'Other ungulates' were goat (Oreamnos americanus) and moose (Alces alces). Deer are Odocoileus hemionus.

Specifically, the probability of wolves foraging on deer declined primarily with increased island isolation from the mainland, but less so with isolation from other landmasses and smaller island area (Table 2; Fig. 3). All five models in the top model set $\left(0-2 \Delta \mathrm{AIC}_{\mathrm{c}}\right)$ contained MDIST. Considerable ambiguity, however, existed among top models, which had similar Akaike weights $\left(\omega_{\mathrm{i}=1}\right.$ to $5=0.21$ to 0.08 ; Table 2$)$. Moreover, these top models explained a similar proportion of the variance (Nagelkerke $R^{2}$ range $=0.218-0.242$; note that pseudo $R^{2}$ values for logistic regression are lower than would be expected in a linear model; Table 2). In cases when the data do not strongly support a single best model, however, the one with fewest parameters is often worth most consideration, following the rule of parsimony (Burnham \& Anderson, 1998). Accordingly, we consider model 4, containing only the intercept and MDIST, as a preferred model (Table 2).

The top model set can still make robust multimodel inference (Burnham \& Anderson, 1998); summing the Akaike weights across top models ranked the variable MDIST $\left(\Sigma \omega_{\mathrm{i}}=0.74\right)$ higher than LDIST and AREA $\left(\Sigma \omega_{\mathrm{i}}=\right.$ 0.35 and 0.27 ) by factors of 2.11 and 2.74 respectively. Moreover, the strength of coefficients associated with isolation metrics was much higher than those for area, which approached zero (Table 2). Interaction terms MDIST $\times$ LDIST $\left(\Sigma \omega_{\mathrm{i}}=0.20\right)$ and AREA $\times$ MDIST $\left(\Sigma \omega_{\mathrm{i}}=0.20\right)$ were less important.

\section{DISCUSSION}

Islands provide ideal model systems for studying predatorprey interactions (e.g. Peterson et al., 1984). Often, however, isolated islands lack predators and even on less isolated islands mammalian carnivores are relatively rare (Williamson, 1981; Alcover \& McMinn, 1994). Consequently, our knowledge of predator-prey dynamics in isolated systems is limited. Moreover, our ecological knowledge of coastal temperate rain forests of North America is in its infancy (MacDonald \& Cook, 1996). Herein we examine the foraging ecology of BC's coastal wolves and provide additional insight into predator-prey dynamics in fragmented landscapes. Specifically, we partitioned the variability we observed to spatial features of the landscape, both on a gross geographical scale (mainland, inner and outer islands) and with finer resolution by disentangling the effects of area and isolation.

Across their holarctic distribution, wolves hunt a diverse suite of animals (Paquet \& Carbyn, 2003; Peterson \& Ciucci, 2003). Here we show high trophic diversity and variability among wolves within a single biome. On BC's coast, we observed a minimum of 14 terrestrial mammals, a marine mammal, salmon, birds and marine invertebrates in diet. We did not detect any 'species richness' effects (narrower dietary niche for wolves on isolated islands), perhaps because these prey taxa are not as sensitive as others to biogeographical effects of isolation. Prey detected across this landscape greatly exceeds the number of items identified in earlier studies in the same biome [Scott \& Shackleton, 1980 (Vancouver Island; 3 items); Milne et al., 1989 (Vancouver Island; 4 items); Kohira \& Rexstad, 1997 (Southeast Alaska; 11 items)]. This difference may reflect our greater geographical span of sampling and a more rigorous laboratory protocol. 


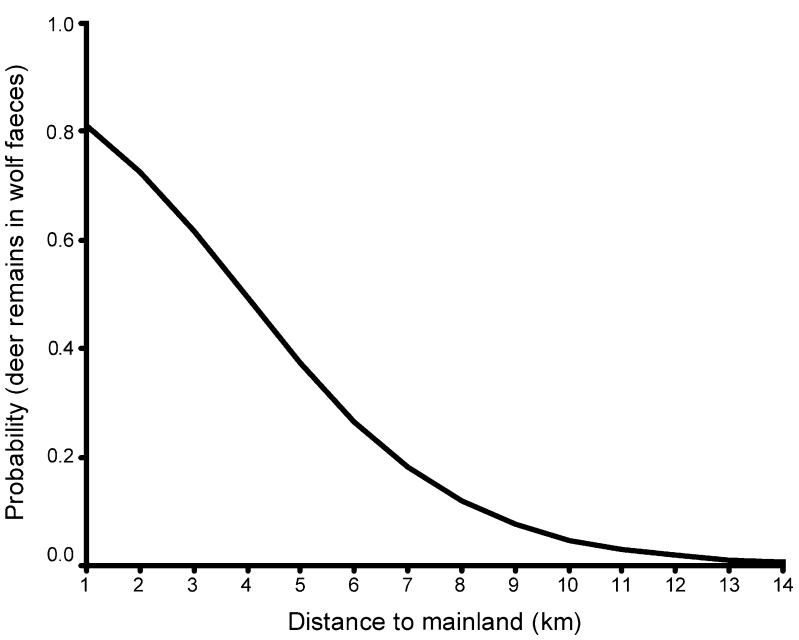

Figure 3 Probability of deer (Odocoileus hemionus) remains occurring in wolf (Canis lupus) faeces on islands as a function of their distance to the mainland (MDIST). Samples collected in coastal British Columbia, summers 2000 and 2001. Equation: $Y=1.915-0.494 \times$ MDIST, which forms the simplest model in our top model set based on Akaike Information Criteria ranking.

Additional spatial and temporal aspects of our sampling may explain differences with previous studies. Sampling within $5 \mathrm{~km}$ of shoreline may explain the abundance of smaller prey consumed. For example, marine invertebrates accounted for approximately $4 \%$ of prey items we detected. In addition, river otter and mink, which accounted for a combined 5.9\%, are primarily occupants of the beach fringe. Moreover, we detected beaver in $<3 \%$ of scats, which differs greatly from other North American studies in which they occurred much more commonly (Voigt et al., 1976; Fuller, 1989; Thurber \& Peterson, 1993). This too may reflect our sampling bias of omitting much of the inland area, and/or a naturally low abundance of beaver in this conifer-dominated landscape (McCabe, 1948). Also, because faecal samples represented late spring and summer diet, more than half a year of dietary information was excluded. Early runs of spawning salmon accounted for the second highest proportion of prey consumed by wolves $(6.5 \%)$ and recent stable isotope and behavioural evidence suggest that salmon runs during late summer and autumn support a major seasonal shift in the foraging of coastal wolves (Szepanski et al., 1999; Darimont \& Reimchen, 2002; Darimont et al., 2003).

Major changes in the predation regime occurred across broad geographical categories, possibly because of associated habitat differences. Wolves consume less deer in rocky mainland areas compared with nearby but less mountainous inner islands (Figs $1 \& 2$ ). This may relate to low deer biomass per area on the mainland where elevations $>1100 \mathrm{~m}$ are common, altitudes at which deer in nearby southeast Alaska are known not to occur (Schoen \& Kirchhoff, 1985). Although no similar data exist for BC's coast, deer densities in southeast Alaska are lower on the mainland coast compared with adjacent inner islands (Kirchhoff, 1996). Alternatively or 
concomitantly, the lower observed frequency of deer in wolf diet on the mainland can be attributed to a more species-rich prey assemblage in mainland watersheds. For example, mountain goat and moose are two large terrestrial mammals that predominantly occupy mainland habitats and provided an additional food resource.

Predator-prey dynamics in fragmented landscapes may be determined by area of fragments, their isolation, and systemspecific factors, which in coastal BC may include carrying capacity for deer. Similar to mainland areas, habitat on outer islands may support fewer deer. Thus, the lower frequency of this item in wolf diet may reflect lower availability. We consider this unlikely to serve as the full explanation. Similar outer islands, but those lacking wolves, in southeast Alaska and Haida Gwaii, BC, support (or supported before wolf introduction) high populations of deer (Reimchen et al., in press; Kirchhoff, 1994, 1996; Klein, 1996). Likewise, on a recent survey of the Goose Group of islands (c. $25 \mathrm{~km}^{2}$ ), an outer archipelago at least $7 \mathrm{~km}$ from the nearest habitable island, we noted an absence of wolves and severe over browsing of vegetation by deer, suggesting high deer densities (Darimont \& Paquet, 2000, 2002). Deer density data for islands in this archipelago would aid in evaluating this hypothesis.

Among biogeographical parameters to predict the occurrence of deer in wolf faeces, we found isolation, specifically distance to mainland, to be more important than area, likely because it influences dispersal. Regardless of carrying capacity, predators may deplete resources in isolated fragments if colonization by prey is limited. We consider this a plausible hypothesis for wolf-deer systems on isolated islands of coastal BC. We postulate that greater distances to mainland reduce immigration rates by deer, predisposing island populations to sustained predation by wolves. Neither area nor the interaction between isolation and area was very important, perhaps because the ecological conditions we deduce from our onetime sampling represent a steady state: over time wolves regulate deer on isolated islands to low abundance, regardless of island size.

Deer are excellent dispersers, however, capable of swimming across water bodies with intense and frequent wave and tidal action (Wallmo, 1981). Reimchen et al. (in press) examined deer colonization rates to offshore islands of Haida Gwaii, BC, using microsatellite markers. These authors made a conservative estimate of persistent dispersal of about one deer per year to Skaang Gwaii and Reef Islands, isolated by 2 and $6 \mathrm{~km}$ respectively. If colonization rates are similar in $\mathrm{BC}$, our data suggest this is too infrequent to prevent depletion of deer prey on isolated islands. Mainland distance may have been more important than our inter-landmass metric because it estimates distance from the probable ultimate source populations for deer prey.

Our single sampling of this archipelago revealed a pattern of decreased occurrence of deer as prey with isolation, to which we attribute top-down effects coupled with limited recolonization by deer. To be certain, one must sample islands before and after wolf colonization and estimate deer abundance and wolf foraging ecology over time. In the 1960s, a small experiment addressed these parameters by introducing four wolves to the $73 \mathrm{~km}^{2}$ Coronation Island, southeast Alaska, 900-m from another landmass (Klein, 1996). After reaching a peak of 13 wolves in 4 years, the population fell to one, having apparently reduced deer numbers significantly. During this time, wolves foraged extensively on smaller mammals, seals and intertidal organisms (Klein, 1996). The last wolf was shot in the late 1960s, ending the experiment, and the deer population has since rebounded (Person et al., 1996).

Others have demonstrated the consequences of insularity on mammalian predator-prey communities on islands but the dynamics of these systems vary. On Isle Royale, fluctuations of wolves and moose have been extreme but this system has persisted for over 50 years (Peterson et al., 1984; Peterson \& Page, 1988; Vucetich \& Peterson in press). In contrast, Kauhala \& Auniola (2001) suggested that raccoon dogs (Nyctereutes procyonoides) can extirpate frog populations on some islands in the Finnish Archipelago, as they are easy prey to capture and occur frequently in mainland diet. Migration by predators among landmasses may also be important; by switching between islands and mainland areas from winter to summer, foxes can stabilize fluctuations in hare numbers on Swedish islands, but the effect depends on how often ice permits foxes to recolonize islands and numerical response by predators (Angerbjörn, 1989).

Wolves may persist on isolated islands because alternate prey are available. When deer are scarce (and other large mammals like goat and moose absent), smaller prey such as mink, river otter and bird, appear to be important dietary items (Table 1; Fig. 2). Many of these taxa are either aquatic or volant and not likely as affected by isolation that may limit migration by larger, terrestrial prey.

Future studies in BC's archipelago, combining stable isotope and faecal analyses and occurring over several seasons, may provide better insight into predator-prey dynamics in this fragmented marine landscape. Notably, if combined with microsatellite genetic markers, we may learn how food resources influence presence, movements and demographical fates of individuals over time and assess how water barriers among islands may affect metapopulation dynamics (Hanski \& Gilpin, 1991; Hanski, 1991); such frameworks for other large mammals in habitat patches have recently been developed (e.g. Elmhagen \& Angerbjörn, 2001). Notably, although water barriers may constrain dispersal of predator and prey, this study suggests the ocean also provides food. In this respect, for wolves and likely other animals, BC's islands are not fragments within a totally inhospitable matrix, to which other islands have been likened (Brotons et al., 2003; see also Dunning et al., 1992; Fahrig, 1997).

This study has implications for conservation of predatorprey systems regionally and beyond. Deer constitute the majority of diet for BC's coastal wolves and salmon is an important seasonal resource (this study; Kohira \& Rexstad, 1997; Szepanski et al., 1999; Darimont \& Reimchen, 2002; 
Darimont et al., 2003). Mounting evidence, however, suggests that carrying capacity for deer is reduced by clearcut logging in west coast temperate rain forests (Wallmo \& Schoen, 1980; Alaback, 1982; Rose, 1982; Schoen et al., 1984, 1988; Van Horne et al., 1988). Likewise, many Pacific Northwest salmon stocks have declined dramatically because of the modification of spawning habitat by logging and over-exploitation by the fishing industry (National Resources Council, 1996). If current planning processes aim to preserve this remnant population of wolves in its current form (Darimont \& Paquet, 2002), we suggest that plans include significant protection of critical habitat for deer and salmon, especially on islands. Moreover, in any ecosystem, a system of reserves must have appropriate connectivity to permit gene flow (Soule \& Simberloff, 1986). Our data suggest that connectivity should also be considered to accommodate fluctuations in population structure to prevent predator-prey disequilibria, to which fragments may already be predisposed.

\section{ACKNOWLEDGMENTS}

This study took place in the Traditional Territories of several First Nation groups, from whom we sought permission before research begun. We are extremely grateful to the Raincoast Conservation Society for financial and logistical support as well as the Heiltsuk Nation for their participation. We are obliged to Chris Genovali, Ian and Karen McAllister, Misty MacDuffee, Gudrun Pfleuger, Anita Rocamora, Chester Starr, and Erin Urton for fieldwork, and skippers Jean-Marc Leguerrier and Dave Lutz. We also thank Richard Ring, Becky Wiggen and Eric Lofroth. The Defenders of Wildlife, McCaw Foundation, National Geographic Society, University of Montana Paquet Wildlife Fund, Wilburforce, Vancouver Foundation, World Wildlife Fund Canada and private donors kindly provided funding. While preparing the manuscript, CTD was supported by a Natural Sciences and Engineering Research Council (NSERC) - Industrial Post-graduate Scholarship and NNW by a NSERC operating grant. We thank B. Anholt, R. Page, D. Person, T. Reimchen and two reviewers for comments that greatly improved the manuscript.

\section{REFERENCES}

Abbott, I. (1974) Numbers of plant, insect and land bird species on nineteen remote islands in the Southern Hemisphere. Biological Journal of the Linnaean Society, 6, 143-152.

Alaback, P.B. (1982) Dynamics of understory biomass in Sitka spruce-western hemlock forests of southeast Alaska. Ecology, 63, 1932-1948.

Alcover, J.A. \& McMinn, M. (1994) Predators of vertebrates on islands. Bioscience, 44, 12-18.

Anderson, D.R., Link, W.A., Johnson, D.H. \& Burham, K.P. (2001) Suggestions for presenting the results of data analyses. Journal of Wildlife Management, 65, 373-378.

Angerbjörn, A. (1989) Mountain hare populations on islands: effects of predation by red fox. Oecologia, 81, 335-340.
Brotons, L., Mönkkönen, M. \& Martin, J.L. (2003) Are fragments islands? Landscape context and density-area relationships in Boreal forest birds. American Naturalist, 162, 343-357.

Burnham, K.P. \& Anderson, D.R. (1998) Model selection and inference: a practical information-theoretic approach. Springer-Verlag, New York, NY, USA.

Ciucci, P., Boitani, L., Pelliccioni, E.R., Rocco, M. \& Guy, I. (1996) A comparison of scat-analysis methods to assess the diet of the wolf Canis lupus. Wildlife Biology, 2, 37-48.

Conroy, C.J., Demboski, J.R. \& Cook, J.A. (1999) Mammalian biogeography of the Alexander Archipelago of Alaska: a north temperate nested fauna. Journal of Biogeography, 26, 343-352.

Cowen, I.M. \& Guiguet, C.J. (1975) The mammals of British Columbia. British Columbia Provincial Museum, Victoria, BC.

Crooks, K.R. \& Soulé, M.E. (1999) Mesopredator release and avifaunal extinctions in a fragmented system. Nature, 400, 563-565.

Darimont, C.T. \& Paquet, P.C. (2000) The gray wolves (Canis lupus) of British Columbia's coastal rainforests: findings from year 2000 pilot study and conservation assessment. Prepared for the, Raincoast Conservation Society, Victoria, BC. Available on http://www.raincoast.org.

Darimont, C.T. \& Paquet, P.C. (2002) The gray wolves, Canis lupus, of British Columbia's Central and North Coast: distribution and conservation assessment. Canadian FieldNaturalist, 116, 416-422.

Darimont, C.T. \& Reimchen, T.E. (2002) Intra-hair stable isotope analysis implies seasonal shift to salmon in gray wolf diet. Canadian Journal of Zoology, 80, 1638-1642.

Darimont, C.T., Reimchen, T.E. \& Paquet, P.C. (2003) Foraging behaviour by gray wolves on salmon streams in coastal British Columbia. Canadian Journal of Zoology, 81, 349-353.

Dolman, P.M. \& Sutherland, W.J. (1997) Spatial patterns of depletion imposed by foraging vertebrates: theory, review and meta-analysis. Journal of Animal Ecology, 66, 481-494.

Dunning, J.B., Danielson, J.B. \& Pulliam, H.R. (1992) Ecological processes that affect populations in complex landscapes. Oikos, 65, 169-175.

Elmhagen, B. \& Angerbjörn, A. (2001) The applicability of metapopulation theory to large mammals. Oikos, 94, 89-100.

Fahrig, L. (1997) Relative effects of habitat loss and fragmentation on species extinction. Journal of Wildlife Management, 61, 603-610.

Fahrig, L. (2003) Effects of habitat fragmentation on diversity. Annual Review of Ecological Systems, 34, 487-515.

Fuller, T.K. (1989) Population dynamics of wolves in northcentral Minnesota. Wildlife Monographs, 105, 1-41.

Gorman, M.L. (1979) Island ecology. Chapman and Hall, New York, NY, USA.

Hanski, I. (1991) Single-species metapopulation dynamics: concepts, models and observations. Biological Journal of the Linnaean Society, 42, 17-38. 
Hanski, I. \& Gilpin, M. (1991) Metapopulation dynamics: brief history and conceptual domain. Biological Journal of the Linnaean Society, 42, 3-16.

Kadmon, R. \& Pulliam, H.R. (1993) Island biogeography: effects of geographical isolation on species composition. Ecology, 74, 977-981.

Kareiva, P. (1990) Population dynamics in spatially complex environments: theory and data. Philosophical Transactions of the Royal Society of London, Series B. Biological Sciences, 330, 175-190.

Kareiva, P. \& Wennergren, U. 1995. Connecting landscape patterns to ecosystem and population processes. Nature, 373, 299-302.

Kauhala, K. \& Auniola, M. (2001) Diet of raccoon dogs in summer in the Finnish archipelago. Ecography, 24, 151-156.

Kirchhoff, M.D. (1994) Effects of forest fragmentation on deer in southeast Alaska. Unpublished Management Report. Alaska Department of Fish and Game, Juneau, AK, USA.

Kirchhoff, M.D. (1996) Deer pellet-group surveys in southeast Alaska. Unpublished Management Report. Alaska Department of Fish and Game, Douglas, AK, USA.

Klein, D.R. (1996) The introduction, increase and demise of wolves on Coronation Island, Alaska. Ecology and conservation of wolves in a changing world (ed. by L.N. Carbyn, S.H. Fritts and D.R. Seip), pp. 275-280. Canadian Circumpolar Institute, University of Alberta, Edmonton, AB.

Kohira, M. \& Rexstad, E.U. (1997) Diets of wolves, Canis lupus, in logged and unlogged forests of southeastern Alaska. Canadian Field-Naturalist, 111, 429-435.

MacArthur, R.H. \& Pianka, E.R. (1966) On optimal use of a patchy environment. American Naturalist, 100, 603-609.

MacArthur, R.H. \& Wilson, E.O. (1967) The theory of island biogeography: monographs in population biology. Princeton University Press, Princeton, NJ, USA.

MacDonald, S.O. \& Cook, J.A. (1996) The land mammal fauna of Southeast Alaska. Canadian Field-Naturalist, 110, 571598.

Mathiak, H.A. (1938) A key to hairs of the mammals of southern Michigan. Journal of Wildlife Management, 2, 251268.

Mayer, W.V. (1952) The hair of California mammals with the keys to the dorsal guard hairs of California mammals. American Midland Naturalist, 38, 480-512.

McCabe, T.T. (1948) Beaver on the northern British Columbian islands. Canadian Field-Naturalist, 62, 72-74.

McCauley, E., Kendall, B.E., Janssen, A., Wood, S., Murdoch, W.W., Hosseini, P., Briggs, C.J., Ellner, S.P., Nisbet, R.M., Sabelis, M.W. \& Turchin, P. (2000) Inferring colonization processes from population dynamics in spatially structured predator-prey systems. Ecology, 81, 3350-3361.

Milne, D.G., Harestad, A.S. \& Atkinson, K. (1989) Diets of wolves on northern Vancouver Island. Northwest Science, 63, 83-86.

National Resources Council (1996) Upstream: salmon and society in the Pacific Northwest. National Academy Press, Washington, DC, USA.
Paquet, P.C. \& Carbyn, L.N. (2003) Wolf, Canis lupus. Wild mammals of North America: biology, management, and conservation (ed. by G.A. Feldhamer, B.C. Thompson and J.A. Chapman), Johns Hopkins University Press, Baltimore, MD, USA.

Person, D.K., Kirchhoff, M.D., Van Ballenberghe, V., Iverson, G.C. \& Grossman, E. 1996. The Alexander Archipelago wolf: a conservation assessment. General Technical Report PNWGTR-384. USDA Forest Service, Portland, OR, USA.

Peterson, R.O. \& Ciucci, P. (2003) The wolf as a carnivore. Wolves. Behaviour, ecology and conservation (ed. by L.D. Mech and L. Boitani), pp. 104-130. University of Chicago Press, Chicago, IL, USA.

Peterson, R.O. \& Page, R.E. (1988) The rise and fall of Isle Royale wolves. Journal of Mammalogy, 69, 89-99.

Peterson, R.O., Page, R.E. \& Dodge, K.M. (1984) Wolves, moose and allometry of population cycles. Science, 224, 1350-1352.

Pojar, J. \& Mackinnon, A. (1994) Plants of coastal British Columbia, including Washington, Oregon, and Alaska. Lone Pine Publishing, Vancouver, BC.

Polis, G.A. \& Hurd, S.D. (1995) Extraordinarily high spider densities on islands: flow of energy from the marine to terrestrial food webs and the absence of predation. Proceedings of the National Academy of Sciences of the United States or America, 92, 4382-4386.

Reimchen, T.E. (2000) Some ecological and evolutionary aspects of bear-salmon interactions in coastal British Columbia. Canadian Journal of Zoology, 78, 448-457.

Reimchen, T.E., Nelson, R.J. \& Smith, C.J. (in press) Estimating deer colonization rates to offshore islands of Haida Gwaii, British Columbia, using microsatellite markers. Lessons from the islands: introduced species and what they tell us about how ecosystems work (ed. by A.J. Gaston, T.E. Golumbia, J.-L. Martin and S.T. Sharpe). Proceedings from the Research Group on Introduced Species 2002 Conference. Queen Charlotte City, B.C. Canadian Wildlife Service Occasional Papers Series, Ottawa, ON.

Ricklefs, R.E. (1990) Ecology. W.H. Freeman and Co., New York, NY, USA.

Rose, C.L. (1982) Deer responses to forest succession on Annete Island, southeast Alaska. MSc. Thesis. University of Alaska, Fairbanks, AK, USA.

Rose, M.D. \& Polis, G.A. (1998) The distribution and abundance of coyotes: the effects of allochthonous food subsidies from the sea. Ecology, 79, 998-1007.

Saunders, D.A., Hobbs, R.J. \& Margules, C.R. (1991) Biological consequences of ecosystem fragmentation: a review. Conservation Biology, 5, 18-32.

Schneider, M.F. (2001) Habitat loss, fragmentation and predator impact: spatial implications for prey conservation. Journal of Applied Ecology, 38, 720-735.

Schoen, J.W. \& Kirchhoff, M.D. (1985) Seasonal distribution and home-range patterns of Sitka black-tailed deer on Admiralty Island, southeast Alaska. Journal of Wildlife Management, 49, 96-103. 
Schoen, J.W., Kirchhoff, M.D. \& Wallmo, O.C. (1984) Sitka black-tailed deer/old-growth relationships in southeast Alaska: implications for management. Proceedings of the symposium on fish and wildlife relationships in old growth forests (ed. by W.R. Meacham, T.R. Merrell and T.A. Hanley), pp. 315-319. American Institute of Fisheries Research Biologists, Juneau, AK, USA.

Schoen, J.W., Kirchhoff, M.D. \& Hughes, J.H. (1988) Wildlife and old-growth forests in southeastern Alaska. Natural Areas Journal, 8, 138-145.

Scott, B.M.V. (1979) The Vancouver Island Wolf (Canis lupus crassodon), an initial study of food habits and social organization. MSc Thesis, University of British Columbia, Vancouver, BC.

Scott, B.M.V. \& Shackleton, D.M. (1980) Food habits of two Vancouver Island wolf packs: a preliminary study. Canadian Journal of Zoology, 58, 1203-1207.

Soulé, M.E. \& Simberloff, D. (1986) What do genetics and ecology tell us about the design of nature reserves? Biological Conservation, 35, 19-40.

Stains, H.J. (1958) Field guide to guard hair of middle western furbearers. Journal of Wildlife Management, 22, 95-97.

Szepanski, M.M., Ben-David, M. \& Van Ballenberghe, V. (1999) Assessment of anadromous salmon resources in the diet of the Alexander Archipelago wolf using stable isotope analysis. Oecologia, 120, 327-335.

Taylor, R.J. (1984) Predation: population and community bio$\log y$. Chapman and Hall, New York, NY, USA.

Terborgh, J., Lopez, L., Nunez, V.P., Rao, M., Shahabuddin, G., Orihuela, G., Riveros, M., Ascanio, R., Adler, G.H., Lambert, T.D. \& Balbas, L. (2001) Ecological meltdown in predator-free forest fragments. Science, 294, 19231926.

Thurber, J.M. \& Peterson, R.O. (1993) Effects of population density and pack size on the foraging ecology of gray wolves. Journal of Mammalogy, 74, 879-889.

Van Horne, B., Hanley, T.A., Cates, R.G., McKendrick, J.D. \& Horner, J.D. (1988) Influence of seral stage and season on leaf chemistry of southeast Alaska deer forage. Canadian Journal of Forest Research, 18, 90-99.

Voigt, D.R., Kolenosky, G.B. \& Pimlott, D.H. (1976) Changes in summer foods of wolves in Central Ontario. Journal of Wildife Management, 40, 663-668.

Vucetich, J.A. \& Peterson, R.O. (2004) The influence of topdown, bottom-up, and abiotic factors on the moose (Alces alces) population of Isle Royale. Philosophical Transactions of the Royal Society of London, Series B. Biological Sciences, 271, 183-189.

Wallmo, O.C. (1981) Mule and black-tailed deer of North America. University of Nebraska Press, Lincoln, NE, USA.

Wallmo, O.C. \& Schoen, J.W. (1980) Response of deer to secondary forest succession in southeast Alaska. Forest Science, 26, 448-462.

Wallmo, O.C., Jackson, A.W., Hailey, T.L. \& Carlisle, R.W. (1962) Influence of rain on the count of deer pellet groups. Journal of Wildlife Management, 26, 50-55.

Weaver, J.L. (1993) Refining the equation for interpreting prey occurrence in gray wolf scats. Journal of Wildlife Management, 57, 534-538.

Williamson, M. (1981) Island populations. Oxford University Press, New York, NY, USA.

Woodroffe, R. \& Ginsberg, J.R. (1998) Edge effects and the extinction of populations inside protected areas. Science, 280, 2126-2128.

\section{BIOSKETCHES}

Chris Darimont is a $\mathrm{PhD}$ student at the University of Victoria, where his dissertation includes a subset of the study programs designed for the Rainforest Wolf Project. He is particularly interested in marine influences on terrestrial predator-prey systems and spatial ecology, as well as the role of predation risk in maintaining intra-population variability in foraging behaviour of prey.

Michael Price completed his Honours Biology at the University of Victoria on the work herein. He was supervised by Neville Winchester, Adjunct Assistant Professor, whose research focuses on the ecology and conservation of forest canopy invertebrate communiteis.

Johanna Gordon-Walker manages Rainforest Wolf Project field research, as well as collaborates on laboratory work.

Paul Paquet is an internationally recognized authority on the research and conservation of large carnivores and contributes to projects around the world. He is Senior Scientific Advisor for the Rainforest Wolf Project and the Raincoast Conservation Society, Senior Scientist at Conservation Science Inc., and Adjunct Professor at the University of Calgary. 